\title{
Foundation for the Accreditation of Cellular Therapy
}

National Cancer Institute

\section{Source}

National Cancer Institute. Foundation for the Accreditation of Cellular Therapy. NCI

Thesaurus. Code C137949.

A non-profit corporation co-founded by the International Society for Cellular Therapy and the American Society of Blood and Marrow T ransplantation for the purposes of voluntary inspection and accreditation in the field of cellular therapy. Founded in 1996, FACT establishes standards for high quality medical and laboratory practice in cellular therapies. FACT Standards are evidence-based requirements set by world-renowned experts vested in the improvement and progress of cellular therapy. 